\title{
Immunolocalization of phospho-S6 kinases: a new way to detect mitosis in tissue sections and in cell culture
}

\author{
Thomas Schmidt • Patricia Wahl • Rudolf P. Wüthrich • \\ Alexander Vogetseder • Nicolas Picard • \\ Brigitte Kaissling • Michel Le Hir
}

Accepted: 9 November 2006 / Published online: 29 November 2006

(C) Springer-Verlag 2006

\begin{abstract}
During a study on the mTor pathway in the rat kidney we observed a striking increase of the phosphorylation of the S6 kinase in mitosis. In cryostat sections of perfusion-fixed tissue mitotic cells appeared as bright spots in immunofluorescence using an antibody specific for the phosphorylation site Thr421/Ser424. They were easily spotted in overviews with the objective $4 \times$ and $10 \times$. Immunofluorescence was weak during the interphase. During the prophase it increased in both the nucleus and the cytoplasm and it remained bright during the subsequent phases of mitosis. All mitotic cells which were found in tubules and in the interstitium of the kidney using a chromatin stain displayed the bright immunofluorescence for phospho-S6 kinase. The same phenomenon was observed in rat liver and in mouse kidney as well as in a human cell line. Provided a rapid fixation, mitotic cells could be identified with the immunoperoxidase technique in paraffin sections of immersion-fixed tissue. This is the first report of phosphorylation of S6 kinase during mitosis in vivo. Thus, immunohistochemistry with antiphospho-S6 kinase (Thr421/Ser424) appears to provide
\end{abstract}

T. Schmidt $\cdot$ A. Vogetseder $\cdot$ N. Picard $\cdot$ B. Kaissling

M. Le Hir $(\bowtie)$

Institute of Anatomy, University of Zurich,

Winterthurerstrasse 190, 8057 Zurich, Switzerland

e-mail: lehir@anatom.unizh.ch

P. Wahl

Institute of Physiology and Centre for Integrative Physiology,

University of Zurich, Winterthurerstrasse 190,

8057 Zurich, Switzerland

R. P. Wüthrich

Clinic of Nephrology, University Hospital,

Rämistrasse 100, 8091 Zurich, Switzerland a convenient way to detect mitotic cells at low magnification.

\section{Introduction}

The estimation of cell proliferation rates is crucial in studies concerning tissue growth and regeneration as well as regulation of the cell cycle. It is also central for assessment of the malignancy of tumours. Usually, cell proliferation is estimated by immunolabeling of endogenous nuclear proteins, which are up regulated during the progression through the cell cycle, such as cyclin D1, the proliferating cell nuclear antigen (PCNA) or Ki67 (Bartkova et al. 1995; Dobros et al. 1998; Trihia et al. 2003). The detection of thymidine analogues incorporated into newly synthesized DNA is commonly used to reveal DNA synthesis (Miller and Nowakowski 1988). However, none of the methods mentioned above assesses the actual rate of cell division. For instance, DNA synthesis might occur prior to apoptosis or might indicate DNA repair (Jenkins et al. 2001; Khurana et al. 2006). Thus, under some conditions the demonstration of the mitotic phase is crucial.

Most organs display low proliferation rates in adult animals. Mitotic figures are rarely encountered, due to the short duration of the M-phase, in comparison to the other phases of cell cycle. The mitotic phases are well discernible by using chromatin staining. Yet, their detection requires high magnification which makes the screening of large tissue areas tedious and time-consuming.

In a study concerning the mTor pathway in tubular epithelial cells of the rat kidney, we observed that S6 kinase becomes strongly phosphorylated in mitotic 
cells. In order to see whether this phenomenon was restricted to renal epithelia of rats, we included rat livers and mouse kidneys in the study. We found that the phosphorylation of S6-kinase during mitosis was neither species, nor tissue specific. Thus, labelling of phospho-S6 kinase represents a powerful means for the identification of mitotic cells at low magnification.

\section{Materials and methods}

We used 6 weeks old (body weight 140-180 g) male Wistar rats and male C57BL/6 mice (body weight 20$30 \mathrm{~g}$ ). The animals were kept on a standard laboratory diet. The experimental protocol was approved by the Cantonal Veterinary Office of Zürich.

\section{Fixation and tissue treatment}

Rats were anesthetized with pentobarbital $(100 \mathrm{mg} / \mathrm{kg}$ body weight) and mice with a combination of ketamine $(80 \mathrm{mg} / \mathrm{kg}$ body weight) and xylazine $(33 \mathrm{mg} / \mathrm{kg}$ body weight) intraperitoneally. They were fixed by vascular perfusion through the abdominal aorta (Dawson et. al. 1989). The fixative contained $3 \%$ paraformaldehyde, $0.5 \%$ picric acid, $0.01 \%$ glutardialdehyde in a $3: 2$ mixture of $0.1 \mathrm{~mol} / \mathrm{L}$ cacodylate buffer (pH 7.4 adjusted to 300 mosm with sucrose) and 4\% hydroxyl ethyl starch (HES; Fresenius Kabi, Bad Homburg Germany) in $0.9 \% \mathrm{NaCl}$. After $5 \mathrm{~min}$ the fixative was washed out by perfusion with cacodylate sucrose buffer, for $5 \mathrm{~min}$. Kidneys and livers were removed and $2 \mathrm{~mm}$ thick slices were mounted onto thin cork plates and frozen in liquid propane, cooled by liquid nitrogen. The tissue was stored at $-80^{\circ} \mathrm{C}$ until use.

\section{Immunofluorescence}

We used the following primary antibodies: polyclonal rabbit anti-phospho-S6 kinase (Cell Signalling, Danvers, MA), 1:400, which detects p70 S6 kinase when phosphorylated at Thr421/Ser424 as well as p85 S6 kinase phosphorylated at Thr 444/Ser 447; monoclonal mouse anti-alpha-tubulin (Clone B-5-1-2) (Sigma, St Louis MO), 1:400; monoclonal mouse anti-proliferating cell nuclear antigen (PCNA) (clone PC 10) (Dako Cytomation, Glostrup, Denmark) 1:300. The phosphoS6 kinase antibody has been raised by immunization of rabbits with a phosphorylated peptide matching the sequence of human S6 kinase. As stated on the data sheet it has been used successfully for the immunohistochemical detection of phosphor-S6 kinase in tissues of humans, rats and mice.
Four-micrometers thick sections were cut in a cryostat and mounted on chrome-alum-gelatine-coated glass slides. After pre-treatment for $1 \mathrm{~h}$ in $5 \%$ normal goat serum in phosphate buffered saline (PBS), sections were incubated overnight in a humidified chamber with the primary antibodies, diluted in PBS supplemented with $1 \%$ bovine serum albumin. Binding sites of the primary antibodies were revealed with Alexa Fluor 555 goat-anti-rabbit IgG and Alexa Fluor 488 goat-antimouse (Molecular probes, Eugene, OR, USA).

For chromatin staining 4,6-diamidino-2-phenylindole (DAPI; Sigma, St Louis, MO), dilution 1:2,000, was added to the secondary antibodies. After a final rinse with PBS, coverslips were mounted using DAKOglycergel (DakoCytomation Carpinteria CA) to which $2.5 \%$ 1,4-diazybicyclo $(2,2,2)$ octane (DABCO; Sigma, St Louis, MO) was added as fading retardant. For double staining we used cocktails of the primary antibodies as well as of the secondary antibodies.

For immunofluorescence on Hep2 cells subconfluent cultures were fixed for $20 \mathrm{~min}$ at room temperature in $4 \%$ paraformaldehyde, $0.02 \%$ glutardialdehyde in $0.1 \mathrm{M}$ phosphate buffer, $\mathrm{pH}$ 7.3. Further processing was as for cryostat sections.

Immunoperoxidase labelling of phospho-S6 kinase

Rat kidneys were rapidly removed and immediately fixed by immersion in phosphate-buffered freshly depolymerised $4 \%$ paraformaldehyde for $2 \mathrm{~h}$ at $4{ }^{\circ} \mathrm{C}$, dehydrated in alcohol series and embedded in paraffin. Three-micrometer sections were deparaffinized and microwawed for $10 \mathrm{~min}$ in $0.01 \mathrm{M}$ sodium citrate buffer, $\mathrm{pH}$ 6.0. After blocking with $5 \%$ normal goat serum for $30 \mathrm{~min}$ at room temperature the sections were washed in PBS and incubated overnight at $4^{\circ} \mathrm{C}$ with anti-phospho-S6 kinase 1:500 in PBS. The binding sites were revealed by immunoperoxidase using the Vectastain ABC kit (Vector Laboratories, Inc., Burlinghame, CA, USA), with $3,3^{\prime}$-diaminobenzidine as the substrate. The sections were then stained with the periodic acidSchiff reagent.

Terminal desoxy nucleotidyl transferase biotin-dUTP Nick End labelling (TUNEL)

For detection of apoptotic bodies, sections were treated with the TUNEL method using the Terminal Transferase Recombinant Kit 8,000 U (Roche Applied Science, Penzberg, Germany) according to the manufacturer's instructions. Then sections were processed as described above for immunolabeling of phospho-S6 kinase. 


\section{Controls}

For control of unspecific binding of secondary antibodies we made control incubations by omitting the primary antibody. These control experiments were negative.

\section{Microscopic evaluation}

Sections were studied by epifluorescence with a Polyvar microscope (Reichert Jung, Vienna, Austria) equipped with a CCD camera (Visitron, Puching, Germany) and by confocal laser scanning microscopy, using the CLSM SP2 (Leica, Heidelberg, Germany). Images were processed using Image-pro and Photoshop software.

\section{Results}

Phosphorylation of S6 kinase is increased in mitotic cells in rat kidney and liver

In overviews of renal cortex all cell nuclei display a weak immunostaining for phospho-S6 kinase (Fig. 1). Additionally a few bright eye-catching spots can easily be detected. Higher magnification of these cells and analysis of their nuclear configuration by DNA staining with DAPI (Fig. 1 inserts) revealed these spots as mitoses. Mitotic figures which were detected in three kidney sections by DAPI staining were examined for phospho-S6 kinase immunolabeling. All mitotic figures, 52 in tubules and nine in the interstitium, displayed an increased phosphorylation of S6 kinase compared to interphase nuclei. This was further confirmed by double stainings with antibodies against

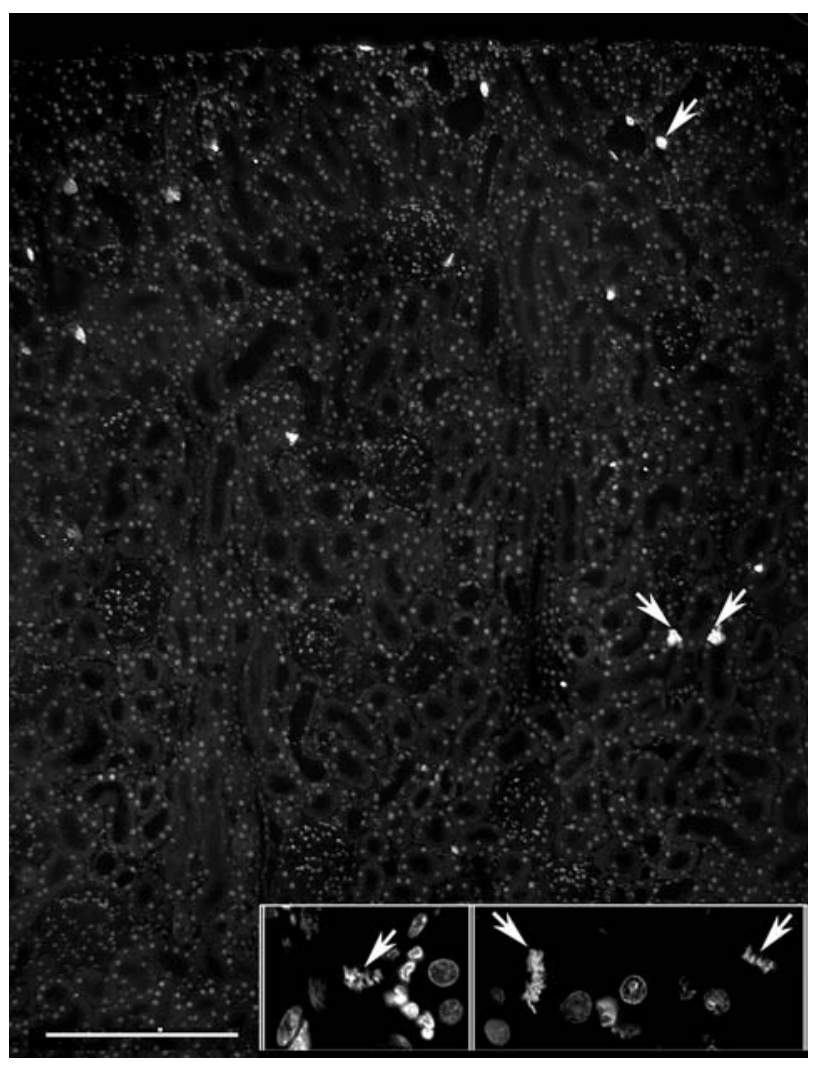

Fig. 1 Overview of a rat kidney cortex; cryostat section, immunofluorescence for phospho-S6 kinase. All nuclei are lightly stained; bright spots correspond to mitotic cells; the chromatin pattern of the spots indicated by arrows in the overview (taken at microscopic magnification $8 \times$ ) is shown in the inserts at $10 \times$ higher magnification by DAPI staining. Bar $200 \mu \mathrm{m}$

alpha-tubulin and phospho-S6 kinase (Fig. 2). Immunostaining for phospho-S6 kinase revealed mitotic cells not only in renal tubules of rats, but also in the interstitium of rat kidneys (Fig. 3a) and in hepatocytes
Fig. 2 Metaphase in rat proximal tubule. a DAPI, blue channel; b phospho-S6 kinase, red channel; $\mathbf{c} \alpha$-tubulin, green channel; d merge. Bar $10 \mu \mathrm{m}$

Fig. 3 Metaphases in different tissues. Phospho-S6 kinase, red channel; $\alpha$-tubulin, green channel; DAPI, blue channel. a Interstitium of rat kidney; b rat hepatocyte; $\mathbf{c}$ interstitium of mouse kidney. Bar $10 \mu \mathrm{m}$
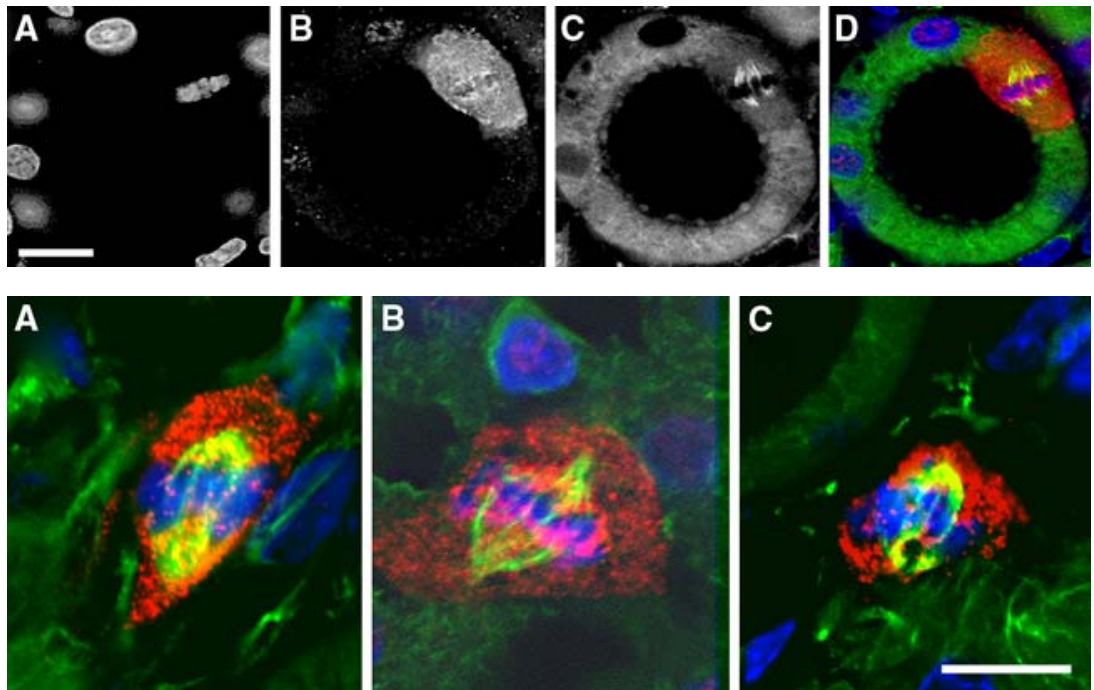
(Fig. 3b). Similar results were obtained in the mouse kidney (Fig. 3c).

The immunoreactivity for phospho-S6 kinase was increased during all phases of mitosis. In co-stainings for alpha-tubulin and phospho-S6 kinase we observed in the prophase (Fig. 4a) when accumulation of tubulin is seen close to the nuclear envelope, very prominent staining for P-S6 kinase between the condensed chromatin and under the nuclear envelope (see also below). In the metaphase (Fig. 4b) bright punctuate staining for phospho-S6 kinase is seen in the whole cytoplasm. Labelling for phospho-S6 kinase remains intense in the anaphase (Fig. 4c).

We also used indirect immunoperoxidase with diaminobenzidin as substrate on immersion-fixed, paraffin-embedded rat kidneys instead of immunofluorescence. Similarly as with immunofluorescence interphase nuclei showed a weak but distinct immunolabeling, whereas mitotic cells displayed a strong signal (Fig. 5). However the latter were not quite as eye-catching as with the immunofluorescence.

The same pattern as in rodent tissues was observed in the human liver tumor cell line Hep2 (Fig. 6).

Phosphorylation of S6-Kinase starts from two distinct pools during prophase in renal tubular cells

In every instance where a nucleus showed a distinctly increased immunolabeling for phospho-S6 kinase it was obvious that the cell was in the prophase since the nucleus was enlarged and chromatin was condensed. As long as the chromosomes were not distinct (Fig. 7d) the nuclear immunolabeling for phospho-S6 kinase was only moderate (Fig. 7a). At this stage a faint immunolabeling in the basal part of the cytoplasm could be seen (Fig. 7a, g) which seemed to correspond to the cell

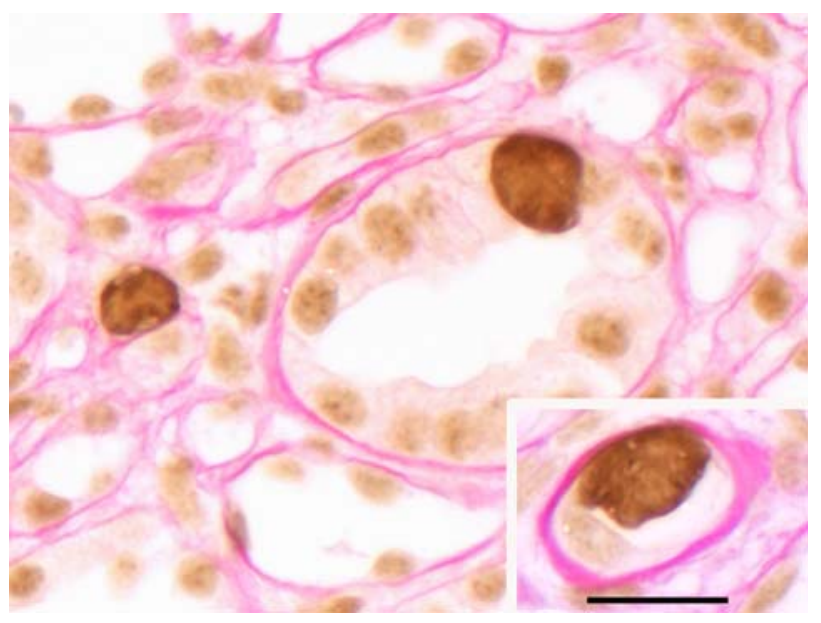

Fig. 5 Localization of phospho-S6 kinase with immunoperoxidase in the rat kidney medulla. Interphase nuclei show a weak staining whereas mitotic cells in a collecting duct, in the interstitium and in the endothelium of a small vessel (insert) are strongly stained. Bar $10 \mu \mathrm{m}$

area which contains the folded basolateral plasma membrane. Both the nuclear and cytoplasmic labelling became stronger (Fig. $7 \mathrm{~b}, \mathrm{~h}$ ) as soon as the chromosomes were discernible within the nuclear envelope (Fig. 7e). At the rupture of the nuclear envelope the labelling was very bright at both sites (Fig. 7c, f, i) and the two pools can no more be distinguished in subsequent phases of mitosis.

S6 kinase is not phosphorylated during S-Phase or in apoptotic cells

Double staining for phospho-S6 kinase and PCNA, which is up-regulated during the late G1-phase and the S-phase, did not show a detectable increase of phosphorylation of S6 kinase during the S-phase (Fig. 8a-c).
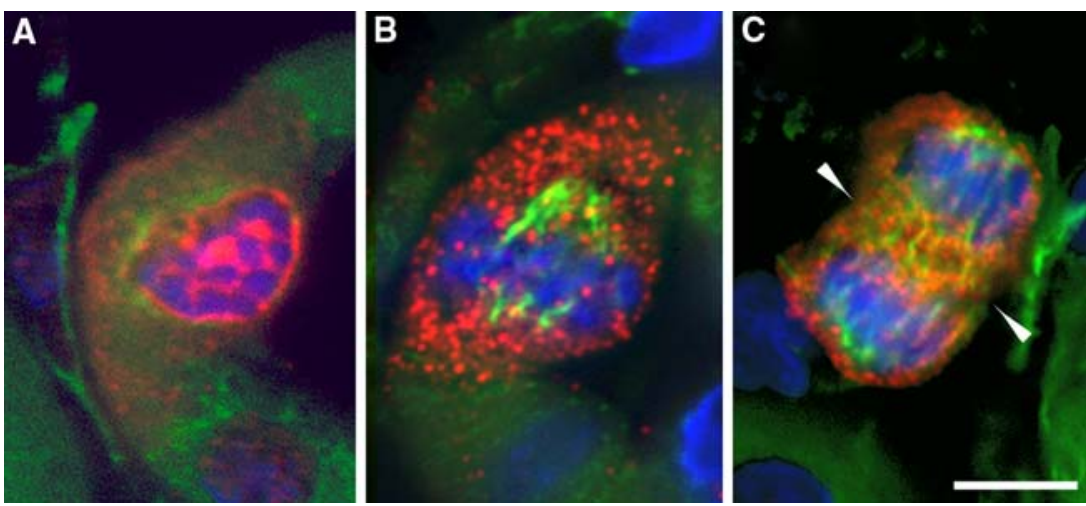

Fig. 4 Various mitotic phases in rat kidney. Blue channel: DAPI; Green Channel: $\alpha$-tubulin; red channel: phospho-S6 kinase. a Prophase: staining for phospho-S6 kinase in the nucleus and the cytoplasm no mitotic spindle; b metaphase: mitotic spindle appar- ent, strong staining for phospho-S6 kinase; c anaphase: staining for phospho-S6 kinase remains high. Arrowheads point to the cleavage plane. Bar $5 \mu \mathrm{m}$ 


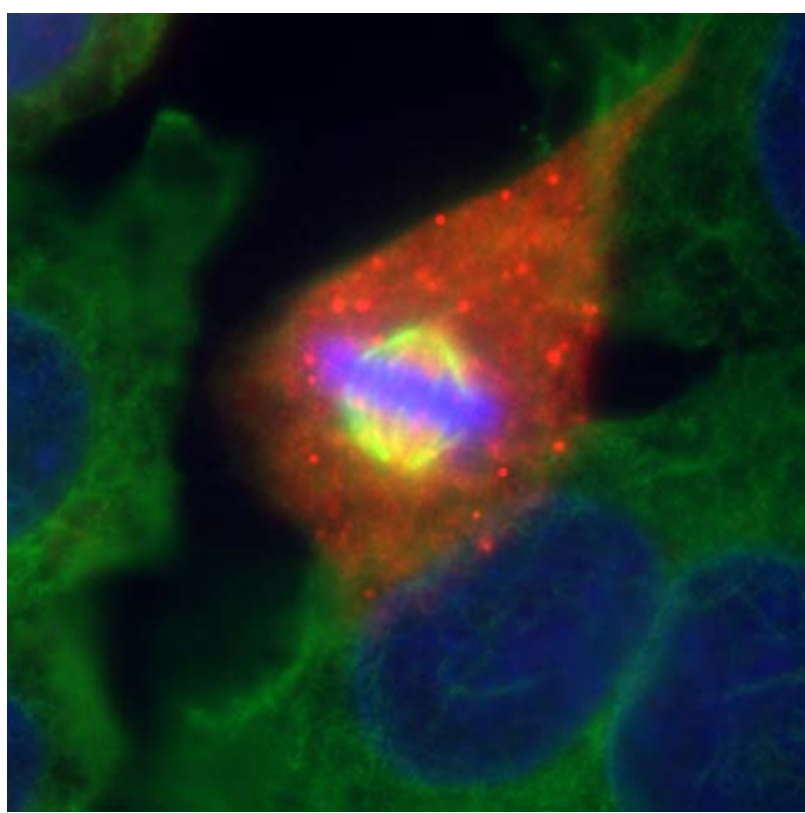

Fig. 6 Immunofluorescent detection of phospho-S6 kinase in Hep2 cells. Phosphorylation of S6 kinase is much higher in the cell in the metaphase than in neighboring interphase cells. Phospho-S6 kinase, red channel; $\alpha$-tubulin, green channel; DAPI , blue channel. Bar $5 \mu \mathrm{m}$
Because the configuration of DNA in mitotic cells is occasionally confused with apoptotic nuclei, we performed double-labelling for phospho-S6 kinase and of apoptotic cell. None of the TUNEL-positive cells showed any labelling for phospho-S6 kinase (Fig. 8d-f).

\section{Discussion}

By staining tissue sections from perfusion-fixed rats and mice with antibodies against phospho-S6-kinase we observed the phosphorylation of S6 kinase at Thr421/Ser424 during mitosis in vivo. The fluorescence for phospho-S6 kinase was bright as soon as chromatin staining revealed the formation of chromosomes during the prophase and it remained bright throughout mitosis. With this technique it was very easy to spot mitotic cells at low magnifications (objectives $4 \times$ or $10 \times)$ in various cell types in rat andmouse tissues and in a human cell line. Using a DNA-binding fluorochrome like DAPI it is then possible identify the phase of mitosis. Phospho-S6 kinase could also be detected in paraffine sections of immersion-fixed tissue. Thus the technique has potentially a broad field of application and it might be useful for evaluating the incidence of mitoses in human pathological samples. However,
Fig. 7 Different stages of prophase. a-c Phospho-S6 kinase; d-f DAPI; $\mathbf{g}-\mathbf{i}$ merge. At an early stage of prophase (a, d, g) phospho-S6 kinase can be detected as a faint staining in the basal part of cytoplasm and staining in the nucleus is somewhat stronger than in normal interphase nuclei. Immunolabeling for phospho-S6 kinase is stronger at a later stage of prophase in both the nucleus and the cytoplasm (b, e, h). The two pools are still largely distinct at the end of the prophase (prometaphase) $(\mathbf{c}, \mathbf{f}, \mathbf{i})$. Bar $5 \mu \mathrm{m}$
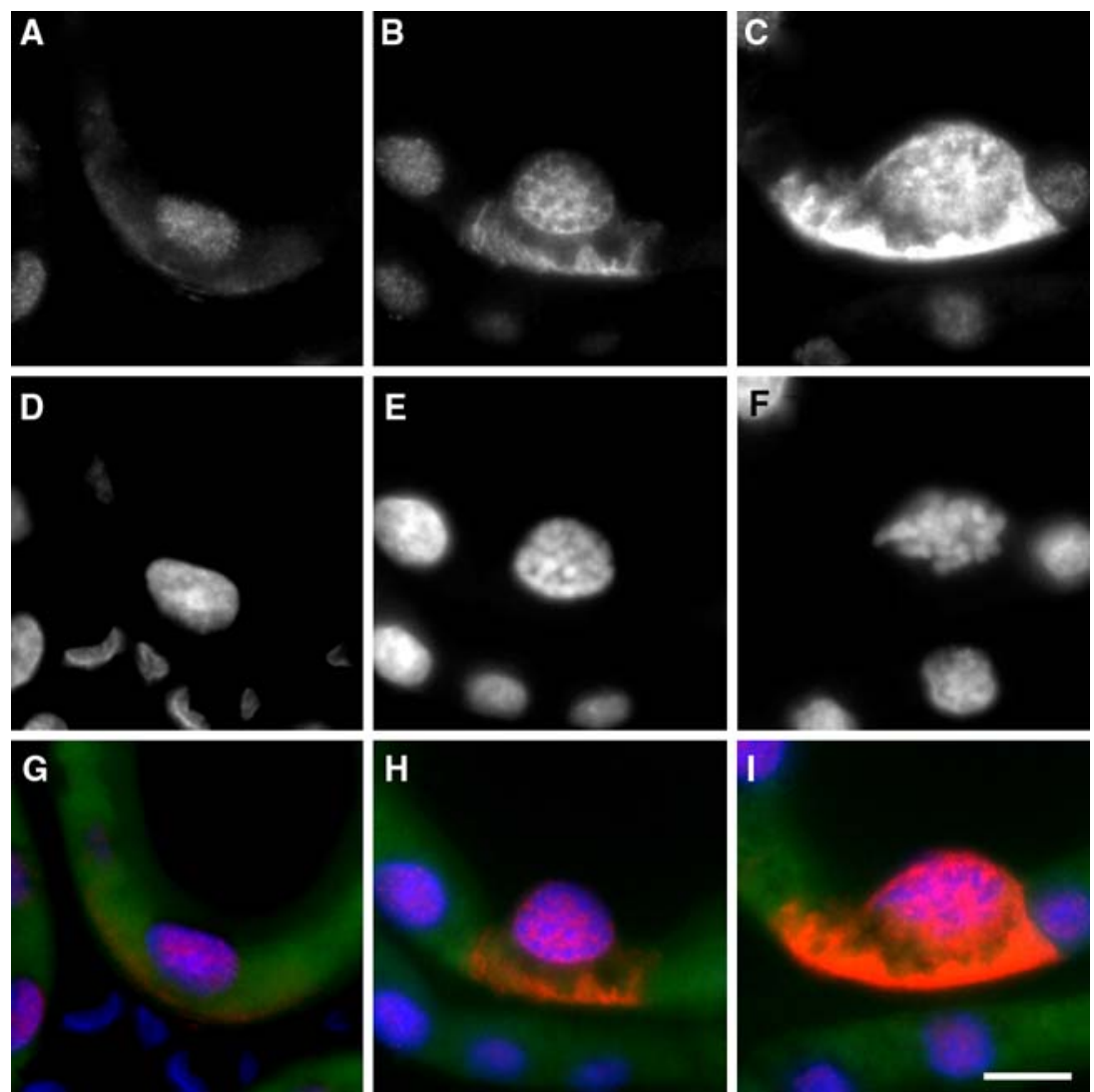
Fig. 8 Immunofluorescence for phospho-S6 kinase is not increased in the $S$ phase of cell cycle or in apoptosis. a-c Double immunolabelling for phospho-S6 kinase (a, red channel) and PCNA (b, green channel), merge (c). d-f Double labelling with anti-phospho-S6 kinase (d, red channel) and TUNEL (e, green channel) and merge (f). Bar $10 \mu \mathrm{m}$
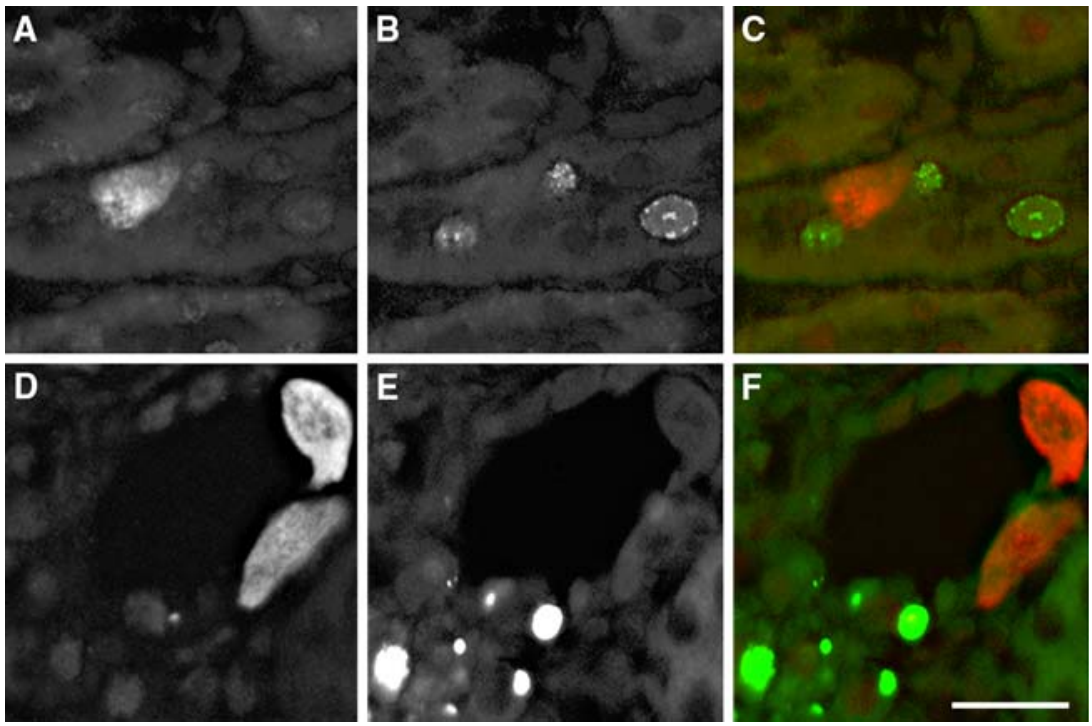

since phosphorylation of proteins is rapidly reversible, it is likely that fixation needs to be carried out quickly after tissue sampling.

Phospho-S6 kinase is downstream of mTOR , which acts as one of the central regulators of cell growth and cell size (Schmelzle and Hall 2000; Harris and Lawrence 2003; Li et al. 2004). Furthermore mTOR plays pivotal roles in establishing cell shape, polarity, migration and proliferation (Neufeld 2003; Berven et al. 2004; Jacinto et al. 2004; Long et al. 2004; Lee et al. 2005a, b; De Virgilio and Loewith 2006). Two different transcripts of phospho-S6 kinase have been described. P70 S6 kinase represents the cytoplasmic form whereas P85 S6 kinase which differs from p70 S6 kinase by a 23 amino acid extension at the amino terminus, is localized in the nucleus (Reinhard et al. 1992, 1994). Phosphorylation of S6 kinase at Ser411 in mitotic cells has been shown in the NIH3T3 cell line but its functional implications remained obscure (Papst et al. 1998). In the present study we observed a large increase of S6 kinase phosphorylation at Thr421/Ser424 during mitosis in tissues of rats and mice. All interphase cells showed a weak nuclear labelling for P-S6 kinase, whereas the cytoplasm remained unlabelled. Mitotic cells however, appeared as bright spots at low magnification. During the prophase phosphorylation of S6 kinase takes place in the nucleus and additionally in the basal cytoplasm of tubule cells. The latter site of phosphorylation might correspond to the basolateral plasma membrane. It has been reported that some kinases bound to the plasma membrane e.g. PDK1, are able to phosphorylate S6-kinase (Alessi et al. 1998).

There is evidence that p85 S6-kinase but not p70 S6 kinase is phosphorylated during the S-Phase (Reinhard et al. 1994). Besides it has been reported that the
mTOR pathway is involved in apoptosis (Jenkins et al. 2001; Khurana et al. 2006). However, double staining for phospho-S6 kinase with PCNA or with TUNEL showed no increased phosphorylation of S6 kinase in the S-Phase or during apoptosis.

The detection of high levels of phospho-S6 kinase in mitotic cells fits to published data. The phosphorylation of S6 kinase at Thr421/Ser424 in cycle-synchronized HeLa cells, as assessed by immunoblotting, increases sharply during mitosis (Shah et al. 2003). The activation of Akt, which is upstream of mTor and of S6 kinase, seems important for the $G_{2} / M$ progression in cell lines (Dangi et al. 2003; Lee et al. 2005a, b). However, the precise function of S6 kinase in mitosis is unknown.

In summary we describe a new way to detect mitotic figures in tissue sections. Immunofluorescence with an antibody against phospho-S6 kinase revealed all mitoses but not cells in the S-phase or apoptotic cells.

Acknowledgments We thank Mrs. Michelle Enderlin for excellent and most careful technical assistance.

Financial support of the study was provided by "Stiftung für wissenschaftliche Forschung an der Universität Zürich".

\section{References}

Alessi DR, Kozlowski MT, Weng QP, Morrice N, Avruch J (1998) 3-Phosphoinositide-dependent protein kinase 1 (PDK1) phosphorylates and activates the p70 S6 kinase in vivo and in vitro. Curr Biol 8:69-81

Bartkova J, Lukas J, Muller H, Strauss M, Gusterson B, Bartek J (1995) Abnormal patterns of D-type cyclin expression and G1 regulation in human head and neck cancer. Cancer Res 55:949-956

Berven LA, Willard FS, Crouch MF (2004) Role of the p70(S6K) pathway in regulating the actin cytoskeleton and cell migration. Exp Cell Res 296:183-195 
Dangi S, Cha H, Shapiro P (2003) Requirement for phosphatidylinositol-3 kinase activity during progression through S-phase and entry into mitosis. Cell Signal 15:667-675

Dawson TP, Gandhi R, Le Hir M, Kaissling B (1989) Ecto-5'nucleotidase: localization in rat kidney by light microscopic histochemical and immunohistochemical methods. J Histochem Cytochem 37(1):39-47

De Virgilio C, Loewith R (2006) The TOR signalling network from yeast to man. Int J Biochem Cell Biol 38:1476-1481

Dobros W, Rys J, Niezabitowski A, Olszewski E (1998) The prognostic value of proliferating cell nuclear antigen (PCNA) in the advanced cancer of larynx. Auris Nasus Larynx 25:295301

Harris TE, Lawrence JC Jr (2003) TOR signaling. Sci STKE 2003:re15

Jacinto E, Loewith R, Schmidt A, Lin S, Ruegg MA, Hall A, Hall MN (2004) Mammalian TOR complex 2 controls the actin cytoskeleton and is rapamycin insensitive. Nat Cell Biol 6:1122-1128

Jenkins JK, Suwannaroj S, Elbourne KB, Ndebele K, McMurray RW (2001) 17-beta-estradiol alters Jurkat lymphocyte cell cycling and induces apoptosis through suppression of Bcl-2 and cyclin A. Int Immunopharmacol 1:1897-1911

Khurana V, Lu Y, Steinhilb ML, Oldham S, Shulman JM, Feany MB (2006) TOR-mediated cell-cycle activation causes neurodegeneration in a Drosophila tauopathy model. Curr Biol 16:230-241

Lee S, Comer FI, Sasaki A, McLeod IX, Duong Y, Okumura K, Yates JR, 3rd, Parent CA, Firtel RA (2005a) TOR complex 2 integrates cell movement during chemotaxis and signal relay in Dictyostelium. Mol Biol Cell 16:4572-4583

Lee SR, Park JH, Park EK, Chung CH, Kang SS, Bang OS (2005b) Akt-induced promotion of cell-cycle progression at G2/M phas involves upregulation of NF-Y binding activity in PC12 cells. J Cell Physiol 205:270-277
Li Y, Corradetti MN, Inoki K, Guan KL (2004) TSC2: filling the GAP in the mTOR signaling pathway. Trends Biochem Sci 29:32-38

Long X, Muller F, Avruch J (2004) TOR action in mammalian cells and in Caenorhabditis elegans. Curr Top Microbiol Immunol 279:115-138

Miller MW, Nowakowski RS (1988) Use of bromodeoxyuridineimmunohistochemistry to examine the proliferation, migration and time of origin of cells in the central nervous system. Brain Res 457:44-52

Neufeld TP (2003) Body building: regulation of shape and size by PI3K/TOR signaling during development. Mech Dev 120:1283-1296

Papst PJ, Sugiyama H, Nagasawa M, Lucas JJ, Maller JL, Terada N (1998) Cc2-cyclin B phosphorylates p70 S6 kinase on Ser411 at mitosisd. J Biol Chem 273:15077-15084

Reinhard C, Fernandez A, Lamb NJ, Thomas G (1994) Nuclear localization of p85s6k: functional requirement for entry into $\mathrm{S}$ phase. EMBO J 13:1557-1565

Reinhard C, Thomas G, Kozma SC (1992) A single gene encodes two isoforms of the p70 S6 kinase: activation upon mitogenic stimulation. Proc Natl Acad Sci USA 89:4052-4056

Schmelzle T, Hall MN (2000) TOR, a central controller of cell growth. Cell 103:253-262

Shah OJ, Ghosh S, Hunter T (2003) Mitotic regulation of ribosomal S6 kinase 1 involves Ser/Thr, Pro phosphorylation of consensus and non-consensus sites by Cdc2. J Biol Chem 278:16433-16442

Trihia H, Murray S, Price K, Gelber RD, Golouh R, Goldhirsch A, Coates AS, Collins J, Castiglione-Gertsch M, Gusterson BA (2003) Ki-67 expression in breast carcinoma: its association with grading systems, clinical parameters, and other prognostic factors-a surrogate marker? Cancer 97:13211331 